\title{
Gefahren des Cyankaliums für Photographen; von Davanne.
}

Die Photographen wenden in enormer Menge zwei der gefährlichsten Gifte an: Cyankalium und Quecksilberchlorid, und bringen sich trotz aller Warnungen auf die unklugste Weise mit denselben in Berübrung. Ein Beispiel! Ein Photograph wollte Silberflecke von seiner Hand durch Reiben mit einem Stücke Cyankalium entfernen, wovon ihm etwas unter den Nagel eines Fingers kam. Er achtete anfangs nicht darauf, wurde bald von Schwindel befallen, so dass sich Alles um ihn zu drehen schien, und kam auf den unglücklichen Gedanken, sich durch Essig zu helfen: das Cyanür wurde sogleich zersetzt und Blausïure gebildet. Der Schwindel wurde stärker, es gesellte sich dazu Frost, bleiche Gesichtsfarbe, getrübter Blick, Schwäche, Unfähigkeit zu reden, die Besinnung blieb jedoch, dann Erkalten der Extremitäten, Doppelsehen. Dieser Zustand dauerte fast 10 Stunden. Kalte Waschungen der Wirbelsäule, Ammoniak-Inhalationen und starker schwarzer Kaffee machten diesem Unfalle ein Ende. (Journ. de Pharm. et de Chim. Nov. 1863.)

Dr. Reich.

\section{Veber las schwefligsaure Trichlormethyl-Chlorür und über die physiologische Wirkungsweise desselben.}

Dieses ron Kö rner in Insbruck gegen Morbus Brigthii als sehr wirksam empfohlene Präparat ist schon seit längerer Zeit unter dem Namen schwefligsaures Koblensuperchlorid $\left(\mathrm{C}^{2} \mathrm{Cl}^{4} \mathrm{~S}^{2} \mathrm{O}^{4}\right)$ bekannt. Man erbält es nach $\mathrm{Kolbe}$ in reichlicher Menge, wenn man Schwefelkohlenstoff längere Zeit mit einer Chlormischung in Berührung erhält und das Gemenge zuletzt destillirt. $2 \mathrm{CS}^{2}+6 \mathrm{Cl}^{2}$ $+4 \mathrm{HO}=\mathrm{C}^{2} \mathrm{Cl}^{4} \mathrm{~S}^{2} \mathrm{O}^{4}+2 \mathrm{SCl}^{2}+4 \mathrm{HCl}$. Das sch wefligsaure Trichlormethyl Chlorür (Chloridum Methylii trichlorati sulfurosum, Carboneum perchloratum sulfurosum) ist eine weisse krystallinische, flüch tige Masse von eigenthümlichem unangenehmen Geruch, in Wasser und Säuren unlöslich; leicht löslich dagegen in Alkohol und Aether; bei $135^{\circ}$ schmilzt, bei $170^{\circ}$ siedet es und sublimirt ohne Zersetzung. Seine Dämpfe wirken in hohem Grade reizend, sie verursachen starkes Thränen, eingeathmet ein unerträgliches Kratzen im Schlunde und anhaltenden Husten, ohne der Gesundheit zu schaden.

Arch. d. Pharm, CLXXIII. Bds. 1.u.2. Hft. 